\title{
Abordagens de Atividades Experimentais no Ensino de Química
}

Juliane Falconieres Santos Oliveira * (Graduanda em Química do Instituto Federal de Educação Ciências e Tecnologia do Rio Grande do Norte - IFRN).

Judiclenia Macedo Santana(Graduanda em Química do Instituto Federal de Educação Ciências e Tecnologia do Rio Grande do Norte - IFRN).

Kely Cristina Fonseca (Graduanda em Química do Instituto Federal de Educação Ciências e Tecnologia do Rio Grande do Norte - IFRN).

Joselma Fonseca de Mendonça (Graduanda em Química do Instituto Federal de Educação Ciências e Tecnologia do Rio Grande do Norte - IFRN).

Carlos Antônio Barros e Silva e Junior ( Prof. do Instituto Federal de Educação Ciências e Tecnologia do Rio Grande do Norte - IFRN)

*Email: Juliane.falconieres@hotmail.com

\section{Resumo:}

A abordagem de atividades experimentais em sala de aula tem sido bastante discutida entre os pesquisadores da área de educação em Ciências, em relação às suas finalidades e tipos de enfoques. Diante disso, este trabalho buscou pesquisar e aplicar, três tipos de atividades experimentais (demonstração, verificação e investigação) procurando melhores condições que facilitem o processo de ensino e aprendizagem de Química, em sala de aula. Com o intuito de investigar as habilidades cognitivas e motivacionais, manifestadas pelos alunos em sala de aula no decorrer de tais atividades experimentais. A aplicação do trabalho aconteceu em uma escola pública de uma turma de $2 \underline{a}$ serie do Ensino Médio, abordando o conteúdo de Cinética Química. Durante a aplicação das atividades experimentais, foi possíveis observar pontos relevantes que favorecem a aprendizagem, como a motivação dos alunos em querer aprender mais sobre o conteúdo, além de sua interação e constante participação com as atividades experimentais abordadas. Mostrando o quanto a utilização de tais atividades experimentais nas aulas de Química pode ser significativa, tanto para a prática docente, quanto para despertar o interesse do aluno.

\section{Palavras-chave:}

Ensino e aprendizagem; habilidades cognitivas; atividades experimentais.

Espaço reservado para organização do congresso. 


\section{I NTRODUÇÃO}

A busca por melhores práticas metodológicas no processo de Ensino e Aprendizagem de Química nas escolas vem recebendo um destaque/atenção por maiores partes dos docentes da disciplina. Nesse sentido, conforme Gil-Peres (2005), Oliveira (2010) e Rosilo (2008) o maior desafio do professor de Ciências e, especialmente de química é tornar os conteúdos da disciplina agradável aos alunos, uma forma de desmistificar e motivar os alunos. Portanto, a abordagem dos professores por práticas experimentais em suas aulas acaba sendo o modo mais adotado para atrair os alunos e possivelmente facilitar o processo de Ensino e Aprendizagem da disciplina.

Segundo Araújo e Abib (2003), a experimentação vem sendo proposta e discutida na literatura de forma bastante diversa quanto ao significado que tais atividades podem assumir no contexto escolar. Esses autores alertam também para o fato de que,

[...] apesar da pesquisa sobre essa temática revelar diferentes tendências e modalidades para o uso da experimentação, essa diversidade, ainda pouco analisada e discutida, não se explicita nos materiais de apoio aos professores. Ao contrário do desejável, a maioria dos manuais de apoio ou livros didáticos disponíveis para auxílio do trabalho dos professores consiste ainda de orientações do tipo "livro de receitas", associadas fortemente a uma abordagem tradicional de ensino [...]. (ARAÚJ O; ABIB, 2003, p.177)

De tal modo, que o aluno é estimulado apenas a seguir um roteiro com caráter de receita como cita o autor, ou ainda uma espécie de manual de instruções. Não atentando-se que $O$ método de realizar aulas experimentais pode beneficiar a criatividade dos alunos das mais diversas formas: instigando que os alunos pesquisem experimentos que considerem importantes e justifiquem suas escolhas; estimulando-os a pensar em possíveis substituições nos materiais empregados no experimento, explicado suas justificativas para tal; colocando-os tanto para executar quanto para auxiliar na montagem do experimento; promovendo o pensar antes da execução do experimento sobre os possíveis resultados a serem obtidos; solicitando que façam desenhos ou esquemas que representem a atividade experimental (BORGES, 2002).

Dentre tudo isso, quanto mais os alunos estiverem envolvidos com as múltiplas etapas da atividade experimental, mais terão sua criatividade estimulada. De acordo com Suart (2009), algo que podemos destacar é que no ensino de Ciências, a dificuldade do aluno em relacionar a teoria desenvolvida em sala com a realidade a sua volta ainda gera um grande conflito de ideias. $E$ isso se estende ainda mais quando esse aluno se encontra no Ensino Médio, especialmente nos conteúdos de Química.

A realização de experimentos, nas aulas de Química, representa uma excelente ferramenta para que o aluno faça a experimentação do conteúdo e possa 
estabelecer a dinâmica e indissociável relação entre teoria e prática. A influência da experimentação no processo de aprendizagem também é discutida por Bazin (1987) que, em uma experiência de ensino não formal de Ciências, aposta na maior significância desta metodologia em relação à simples memorização da informação, método tradicionalmente empregado nas salas de aula.

Araújo e Abib (2003) classificaram as atividades experimentais em três tipos de abordagens ou modalidades (atividades de investigação, de demonstração e de verificação), as quais são apresentadas a seguir:

\subsection{Atividade investigativa}

O ensino por investigação envolve tarefas múltiplas como: a realização de observações; a colocação de questões; a pesquisa em livros e outras fontes de informação; o planeamento de investigações; a revisão do que já se sabe sobre a experiência; a utilização de ferramentas para analisar e interpretar dados; a exploração, a previsão e a resposta à questão; e a comunicação dos resultados.

$\mathrm{Na}$ atividade de investigação o aluno deve projetar e identificar algo interessante a ser resolvido, mas não deve dispor de procedimentos automáticos para chegar a uma solução mais ou menos imediata; a solução, na realidade, deve requerer do aluno um processo de reflexão e tomada de decisões (GI L-PEREZ et al., 2005). O método investigativo tem, então, se revelado eficaz no desenvolvimento de aspectos fundamentais para a educação científica, tais como a possibilidade de fornecer aos alunos oportunidades para o desenvolvimento de habilidades de observação, formulação, teste, discussão, dentre outros.

O professor neste tipo de atividade tem um papel bem distinto daqueles abordados anteriormente. Sua atividade é, sobretudo auxiliar os alunos na busca das explicações causais, negociar estratégias para busca das soluções para o problema, questionar as ideias dos alunos, incentivar a criatividade epistêmica em todas as etapas da atividade, ou seja, ser um mediador entre o grupo e a tarefa, intervindo nos momentos em que há indecisão, falta de clareza ou consenso. Entretanto de demandar mais tempo e exigir mais atenção e auxílio do professor, essa forma de organização da atividade experimental captura a atenção dos alunos e melhora seu envolvimento com a mesma (BORGES, 2002).

Deste modo, enfrentar as situações, quebrar a sua rotina associada a um ensino tradicional e tomar decisões, de forma a ultrapassarem os obstáculos com que se deparam. Nessa abordagem, os alunos têm a oportunidade de discutir, questionar suas hipóteses e ideias iniciais à luz do quadro teórico, coletar e analisar dados para encontrar possíveis soluções para o problema (SUART; MARCONDES 2009).

Apesar de deixar claro que as atividades experimentais praticadas na escola têm funções bem diferentes daquelas realizadas nas universidades e centros de pesquisa, é possível discutir com os alunos aspectos relacionados à natureza da ciência, evitando que eles tenham algumas visões distorcidas da construção do 
conhecimento científico. Segundo Oliveira (2010) a sugestão a ser dada e que o professor destaque, por exemplo, que as observações científicas não são puras ou desprovidas de quaisquer ideias teóricas do observador, ou ainda que não exista um único caminho para a resolução de um problema.

\subsection{Atividade de demonstração}

As atividades demonstrativas é aquela atividade na qual o professor realiza o experimento enquanto os alunos apenas observam os fenômenos ocorridos. Essas atividades são em geral utilizadas para ilustrar alguns aspectos dos conteúdos abordados em aula, tornando-os mais explícito aos alunos e, dessa forma, contribuindo para seu aprendizado. São frequentemente integradas às aulas expositivas, sendo realizadas no seu início, como forma de despertar o interesse do aluno para o tema abordado, ou término da aula, como forma de relembrar os conteúdos apresentados (ARAÚj O; ABIB, 2003).

A realização destes experimentos de forma demonstrativa e algo bastante, proposto, em situações onde exista pouco material, pouco espaço, na qual seja impossível ser realizado com a participação direta de todos, pois o professor pode somente usar esse método como forma de demonstração de uma forma que todos compreendam o experimento e consiga associar com a teoria em si.

Em uma aula demonstrativa, o professor é o principal responsável do processo; cabe a ele exercer o papel de liderança, montar o experimento, fazer questionamentos aos alunos, executar os procedimentos, destacar o que deve ser observado e, sobretudo, permitir as explicações científicas que possibilitam a compreensão do que é observado. Mesmo que a interação entre os alunos não seja tão favorecida, este tipo de experimento favorece uma estreita ligação entre os alunos e o professor; e tal interação social também cria um ambiente propício à aprendizagem (GASPAR; MONTEIRO, 2005).

Dessa maneira, apesar de que as atividades demonstrativas sejam tratadas e definidas pelo qual se deseja falar na aula, na maior parte das vezes não favorecendo mudanças nas discussões com os alunos. É importante propiciar oportunidades para que os alunos possam refletir sobre os fenômenos observados, formulem hipóteses, analisem variáveis que interfiram no experimento, discutam sempre com um olhar mais critico os conteúdos científicos que explicam os fenômenos.

\subsection{Atividade de verificação}

Segundo (ARAÚJ O; ABIB, 2003), a atividade de verificação, é aquela na qual é criada com o objetivo de verificar ou confirmar alguma lei ou teoria. Na qual os resultados de tais experimentos são facilmente previsíveis e as explicações para os fenômenos geralmente conhecidas pelos alunos. Essa atividade proporciona aos alunos a capacidade de interpretar parâmetros que determinam o comportamento dos fenômenos observados, articulando-os com os conceitos científicos que 
conhecem, e de efetuar generalizações, especialmente quando os resultados dos experimentos são extrapolados para novas situações.

$\mathrm{Na}$ atividade de verificação, segundo Borges (2002), vale salientar que mesmo que novas abordagens venham sendo relatados, os experimentos de verificação ainda estão presentes nas práticas adotadas nas escolas, e algumas vantagens foram apontadas pelos professores para sua utilização: os estudantes podem aprender técnicas e a manusear equipamentos; aprendem a seguir direções; requer pouco tempo para preparar e executar; mais fácil de supervisionar e avaliar o resultado final obtido pelos alunos; mais fácil de solucionar problemas que possam surgir durante a execução do experimento; maior probabilidade de acerto, etc.

A aplicação de atividades de verificação é considerada relativamente simples, na qual o professor pode utiliza-la como uma espécie de avaliação inicial de conhecimento dos alunos na qual acaba tornando principalmente aos alunos, nos anos iniciais a se familiariza com experimentos e se acostumar com o método de prática, comprovando os conceitos tratados em aulas teóricas.

Por esse motivo é muito interessante investigar se a prática experimental adotada pelos professores em sala de aula tem facilitado à aprendizagem dos conhecimentos da disciplina. Já que Segundo Rosito (2008), a utilização da experimentação é considerada para o ensino de Ciências, como essencial para a aprendizagem científica. Por isso que deve ser muito bem planejada pelo professor, para que ao final tenha se alcançado os objetivos, e não somente atrair os alunos, mas, sobretudo possibilitar a construção e valorização dos conhecimentos químicos.

Esse trabalho busca investigar o nível de aprendizagem dos alunos de uma turma do 2 o ano do Ensino Médio de uma escola pública. Abordando o tema "Cinética Química". Com o intuito de qualificar por meio de questionários a atividade prática mais significativa no processo de aprendizagem dos alunos. Aonde serão abordados três tipos de atividades práticas: demonstração, verificação e investigação. Classificadas por Araújo e Abib (2003).

\section{METODOLOGIA}

A pesquisa apresenta abordagem qualitativa, uma vez que é direcionada, ao longo de seu desenvolvimento, pois, de acordo com Neves (1996), não busca enumerar ou medir eventos e, geralmente, não emprega instrumental estatístico para análise dos dados. Após as atividades investigativas, foram avaliadas as fichas com questões avaliativas dos conteúdos que foram aplicados para os alunos, analisando assim as concepções, sensações e interpretações que serviriam para os resultados.

O conteúdo de cinética foi escolhido por dar sequência aos próximos assuntos a serem abordados pela professora. Foram usadas duas aulas de Química de 50 minutos cada para aplicar as três abordagens das atividades experimentais. As aulas 
foram apresentadas de modo a não prejudicar a sequência de conteúdos que vinham sendo abordada pela professora. As atividades experimentais foram aplicadas na cidade de Alto do Rodrigues, em uma escola estadual, numa turma da 2 a série do ensino médio.

A sequência didática da aula sobre o conceito de cinética pode ser separadas da seguinte forma:

- Primeiro momento: (Atividade de investigação) A sala foi dividida em quatro grupos, e foram entregues a cada grupo uma folha para as anotações e observações sobre o experimento (segue abaixo).

Anotações sobre o experimento
a) Materiais Utilizados
b) Justificativa
c) Hipótese
d) Tempo e observação
e) Conclusão

Cada grupo desenvolveu uma atividade investigativa diferente, sem nenhum tipo de intervenção no conteúdo ou conceitos. Os experimentos foram divididos para os grupos aleatoriamente, os quatro experimentos escolhidos foram: garrafa pet, com decomposição da carne bovina na água oxigenada, como observação de catalisador; comprimidos efervescentes, demonstração da superfície de contato; comprimidos efervescentes em diferentes concentrações de vinagre e palha de aço com ácido muriático comercial, água em temperatura ambiente e quente, para demonstração da ação da temperatura.

Após a investigação sobre cada experimento os grupos discutiram e apresentaram as suas conclusões para a conceituação final e possíveis generalizações.

- Segundo momento: (Atividade de demonstração) Foram expostos objetos comuns no cotidiano dos alunos que evidenciavam a existência do conteúdo (Cinética Química), tais como: foram usadas frutas cortadas, como a maçã e a banana e expostas naturalmente enquanto os outros pedaços foram adicionados algumas gotas de limão, para demonstrar o escurecimento das frutas e saladas. Foram citadas exemplos do cotidiano como a consenvação do cheiro verde e seu armazenamento; a utilização do carbureto em frutas, a função da geladeira; do sal; entre outras.

- Terceiro momento: (Atividade de Verificação) os alunos receberam um roteiro sobre o experimento chamado: batata espumante, para realizar o experimento já previamente verificado pela professora. Prática simples, onde consistia na observação da reação da água oxigenada com a batata inglesa. Juntamente com o roteiro da prática foi entregue um questionário com perguntas relacionadas ao experimento realizado, com as seguintes perguntas:

1. Você observou algo quando colocou a água oxigenada sobre a sua pele? 
2. Quando se espalhou a água filtrada na superfície de uma das rodelas de batata aconteceu alguma coisa?

3. Qual a sua dedução sobre o que acontece com o contato da: água oxigenada + batata e água oxigenada + pele.

4. O que faz a água oxigenada espumar, tanto no ferimento quanto na batata?

Foram utilizados alguns slides com imagens que demonstravam reações de rapidez e outras que levam longos anos para acontecerem. Os alunos continuaram com o mesmo grupo.

\section{RESULTADOS E DISCUSSÕES}

\subsection{Discussões Sobre a Prática de Investigação}

Na primeira parte, com as atividades investigativas percebeu-se que é possível alcançar diferentes objetivos educacionais. Percebeu-se que esse tipo de atividade proporciona aos alunos participação ativa em todas as etapas do experimento (figura 1), tanto na verificação quanto na investigação das soluções. Verificou-se isso através da leitura das anotações e observações feitas pelos alunos, durante a realização das atividades.

Segundo Oliveira (2010), nesse tipo de abordagem, o professor passa a ser mediador/facilitador do processo. Na execução dessa atividade observou-se que permitiu que os alunos ocupassem uma posição mais ativa no processo de construção do seu próprio conhecimento. Dessa forma, o ambiente de aprendizagem se tornou mais prazeroso, visto que houve uma significativa participação do aluno nesse processo de aprendizagem.
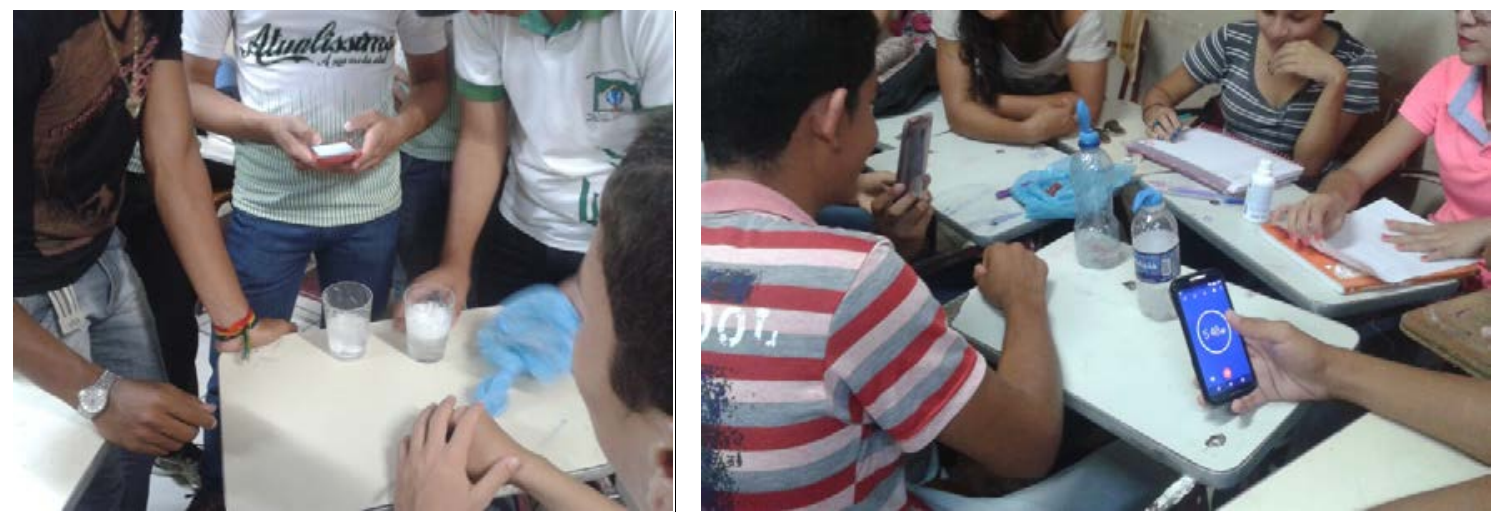

Figura 1: Grupos desenvolvendo as atividades investigativas.

\subsection{Discussões Sobre a Prática Demonstração}

A atividade demonstrativa permitiu ilustrar alguns conteúdos abordados na aula, a participação dos alunos foi eminente, apesar de nessa atividade o professor 
ser o principal agente do processo. Corroborando com as ideias de (OLIVEIRA, 2010). Nesta atividade tonaram-se os alunos mais perceptíveis, dessa forma, contribuindo para seu aprendizado.

$\mathrm{Na}$ demonstração do experimento é mais difícil para manter a atenção dos alunos, quando há apenas observação por parte do aluno não há garantia de que todos estarão envolvidos, mas notou-se uma boa participação dos alunos e estreita relação entre o professor e os alunos.

\subsection{Discussões Sobre a Prática de Verificação}

Os alunos tiveram facilidade na elaboração de explicações para os fenômenos (figura 2), demonstrando que os conceitos abordados foram bem compreendidos. Foi possível verificar através das observações feitas nas respostas ao questionário entregue aos alunos.

Isso foi de encontro com os pensamentos de Oliveira (2010), que os professore que empregam tais atividades em suas aulas destacam que elas servem para motivar os alunos e, sobretudo, para o ensino mais realista e palpável, fazendo com que a abordagem do conteúdo não se restrinja apenas ao livro.

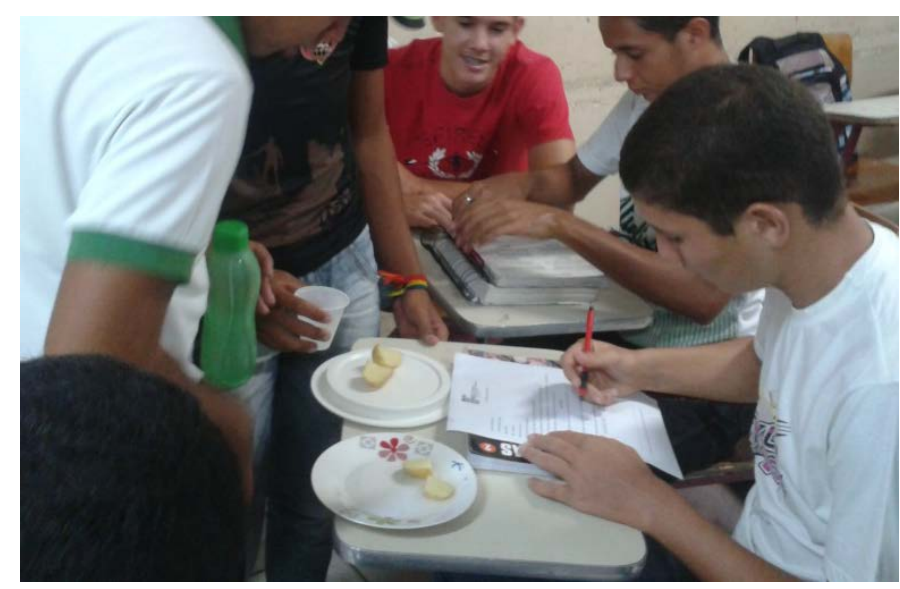

Figura 2: Atividades de verificação.

Ainda que estas atividades apresentem limitações inerentes à sua própria característica, por os alunos não participarem ativamente desta atividade. A condução das atividades pode ser considerada fundamental para que seja alargado o leque de objetivos e o desenvolvimento de posturas e habilidades que podem ser promovidos através de atividades dessa natureza.

\section{CONCLUSÃO}

As atividades experimentais podem ser empregadas com diversas finalidades e através de distintas abordagens, oferecendo importantes contribuições para as aulas de química. É preciso que o professor busque conhecer a diversidade de possibilidades para e ações que the pareçam mais coerentes com o tipo de 
experimento, com a turma, com os recursos, aplicando assim a atividade experimental que lhe for pertinente, buscando desenvolver a habilidade cognitiva do aluno.

Das atividades experimentais descritas neste trabalho, atividades de demonstração, verificação e investigação, podem ser empregadas pelo professor na realização de aulas experimentais. O professor pode aplicar as atividades experimentais sempre utilizando como estratégia a melhor forma para que possam ser aplicadas com objetivos bem definidos e com estratégias que favoreçam, dentro dos limites de cada uma, a máxima eficiência para o aprendizado de novos conteúdos, procedimentos e atitudes. A utilização dessas atividades podem tornar as aulas de química muito mais atraente e motivadora para os alunos.

Experimental Activities Approaches in Chemistry Teaching

Albstract: The approach of experimental activities in the classroom has been much discussed among researchers in the field of education in science, in relation to their purposes and types of approaches. Thus, this study aimed to research and apply three types of experimental activities (demonstration, verification and research) seeking better conditions to facilitate the teaching process and Chemistry learning in the classroom. In order to investigate the cognitive and motivational skills, manifested by students in the classroom in the course of such experimental activities. The implementation of the work took place in a public school in a class of 2 nd series of high school, addressing the content of Chemical Kinetics. During the implementation of the experimental activities, it was possible to observe relevant points that favor learning, as students' motivation in wanting to learn more about content, as well as their interaction and constant involvement with the addressed experimental activities. Showing how the use of such experimental activities in chemistry class can be significant for both the teaching practice, and to arouse the interest of the student.

Keywords: teaching practice; cognitive abilities; experimental activities

\section{REFERÊNCI AS BI BLI OGRÁFI CAS}

ARAÚjO, M. S. T; ABIB, M. L. V. S. Atividades Experimentais no Ensino de Física: diferentes enfoques, diferentes finalidades. Revista Brasileira de Ensino de Física, v.25, n. 2, 2003.

BAZIN, M. Three years of living science in Rio de Janeiro: learning from experience. Scientific Literacy Papers. Secretaria de Educação Fundamental. Parâmetros curriculares nacionais: Ciências Naturais/Secretaria de Educação Fundamental. Brasília: MEC/SEF. Brasil, 1998.

BORGES, A. T. Novos rumos para o laboratório escolar de ciências. Caderno Brasileiro de Ensino de Física, v.19, n.13. 2002.

GASPAR, A.; MONTEIRO, I. C. C. Atividades experimentais de demonstração 
em sala de aula: uma análise segundo o referencia da teoria de Vigotsky. I nvestigações em Ensino de Ciências, v.10, n.2, 2005.

GI L-PEREZ, D. et al. A necessária renovação do ensino das ciências. São Paulo: Cortez Editora, 2005.

ROSITO, B. A. O Ensino de Ciências e a Experimentação. In: MORAES, R. (org.). Construtivismo e Ensino de Ciências: Reflexões Epistemológicas e Metodológicas. Porto Alegre: EDI PUCRS, 2008.

OLIVEI RA, J ane Raquel Silva de. Contribuições e abordagens das atividades experimentais no ensino de ciências: reunindo elementos para a prática docente. Acta Scientiae, Canoas. v. 12 n.1. 2010.

NEVES, Luiz J osé. Pesquisa qualitativa- características, usos e possibilidades. Caderno de pesquisa em administração. São Paulo, v.1, n. 3, 1996.

SUART, Rita de Cássia. MARCONDES, Maria Eunice Ribeiro. A manifestação de habilidades cognitivas em atividades experimentais investigativas no ensino médio de química. Ciências \& Cognição. v. 14. ISSN 1806-5821. 2009. 